\title{
Study on the Performance and Adhesion Behavior of Ultrathin Wearing Course Using Calcined Bauxite as Aggregate
}

\author{
Yanping Sheng $\left(\mathbb{D},{ }^{1}\right.$ Runzhi Wang, ${ }^{1}$ Haichuan Jia $\left(\mathbb{D},{ }^{1}\right.$ Wenli Qiu, ${ }^{2}$ Lei Feng, ${ }^{2}$ Shaobo Zhang, \\ Shian Cui, ${ }^{1}$ and Xiaorui Zhao ${ }^{1}$ \\ ${ }^{1}$ School of Material Science and Engineering, Chang'an University, Xi'an 710064, China \\ ${ }^{2}$ Hebei Xiong'an Jingde Expressway Co., Ltd., Xiong'an, Hebei 071700, China
}

Correspondence should be addressed to Yanping Sheng; shengyanping2003@163.com and Haichuan Jia; hcjia1117@163.com

Received 24 February 2021; Revised 30 May 2021; Accepted 2 July 2021; Published 12 July 2021

Academic Editor: Haibin Li

Copyright (c) 2021 Yanping Sheng et al. This is an open access article distributed under the Creative Commons Attribution License, which permits unrestricted use, distribution, and reproduction in any medium, provided the original work is properly cited.

\begin{abstract}
An ultrathin wearing course is an effective maintenance treatment for prolonging the service life of asphalt pavements, which have been widely used in the field of pavement construction and road maintenance. However, the repeated vehicle load and wear results in a decreased durability of ultrathin wear course cover pavement. Hence, the gradation of ultrathin wear course was designed using calcined bauxite in this study, and the water stability, low-temperature properties, resistance to permanent deformation, and salt erosion were investigated through a laboratory test. Results indicated that the addition of a nonammonia antistripping agent significantly improves the water stability of the asphalt mixture with calcined bauxite and its ability to resist salt erosion as well as improve its low-temperature deformation ability. At the same time, polyphosphoric acid improves the adhesion between asphalt and calcined bauxite aggregate and the high-temperature performance of asphalt mixture but has limited improvement in water stability and resistance to salt erosion. This research is conducive to the widespread use of calcined bauxite aggregates in road pavements and is of great significance for improving the durability of ultrathin wear course asphalt pavements.
\end{abstract}

\section{Introduction}

The ultrathin wear course is suitable for the maintenance and transformation of various asphalt pavement, cement pavement, bridge deck, and tunnel. The unique structure of the ultrathin wear course could be directly overlaid onto the pavement without milling, while hardly having a significant impact on the auxiliary structure and drainage of the asphalt pavement $[1-3]$. At the same time, the weight of the wear course mixture was reduced due to the ultrathin course structure, and the weight increase of the wear course mixture for bridge load was negligible when used for bridging deck overlays. The application of ultrathin course in road pavement has many advantages, such as improving the smoothness of the road surface, increasing the antiskid performance of the road surface, and reducing the driving noise. The surface abrasion courses, as a structural course directly in contact with passing vehicles and the natural environment, require sufficient structural strength, stability, durability, surface smoothness, and surface antiskid performance. Ultrathin wear course is a satisfactory method in highway preventive maintenance, which affects driving safety and comfort during road service [4-6]. However, as the influence of load, light, precipitation, and climate changes, its durability decreases, and its service life dropped to less than ten years. Moreover, the current service level of the ultrathin wear course during the service period is low, such as poor flatness, fast antiskid attenuation, and loud driving noise, which not only reduces driving comfort but also increases noise pollution and traffic safety [7-11]. Therefore, it should not only meet the structural performance requirements but also have sufficient flatness, antiskid performance, wear resistance, low noise, and other functional properties.

Wan et al. [12] proposed that steel slag was used to design an ultrathin wear course for road maintenance with the function of melting ice and snow. The effect of steel slag was characterized by measuring the corresponding 
induction temperature rise and effective induction heating depth. The results showed that steel slag improved the induction heating performance of the pavement friction course. Compared with the hot mix mixture, the steel slagbased mixture has sufficient volume and durability. At the same time, the addition of steel slag also improved the ice and snow melting efficiency of the road friction course. $\mathrm{Hu}$ et al. [13] showed that the porous ultrathin wear course is an effective preventive maintenance measure that can improve road performance and extend service life. Due to the high porosity of the porous asphalt mixture, it provides high drainage capacity and reduces noise, water skiing, water splashing, and spraying. However, the high porosity of this mixture also results in a decrease in strength and looseness resistance compared to densely graded wear courses. Deng et al. [14] developed an ultrathin wear course with high slip resistance and wear resistance using polyurethane as a bonding agent. Experiments and molecular dynamics simulation methods were used to study the properties and nanoadhesion behavior of polyurethane cardboard. The grey correlation method was used to further analyze the relationship between the mechanical properties of aggregates and the antiskid performance of the pavement. The results showed that cemented carbide pavement bricks using emery with a particle size of $2-3 \mathrm{~mm}$ as aggregate exhibit better wear resistance and slip resistance, as well as higher structural stability. Yu et al. [15] proposed a new type of ultrathin asphalt overlay design program, "high-toughness ultrathin friction course." The material properties were optimized and construction technology was designed through laboratory and field tests to evaluate the mechanical and functional properties. The results showed that the hightoughness ultrathin friction course exhibits excellent antislip and noise reduction functions. In addition, the enhancement of the coarse aggregate interlocking and the increase of the asphalt film made it more resistant to fatigue cracking. Amel et al. [16] added nanomontmorillonite materials to asphalt binder, improving the resistance to permanent deformation of asphalt pavements. The test results showed that the asphalt mixture prepared by asphalt containing 3\% nanomontmorillonite has the best resistance to permanent deformation. However, the ultrathin wear course also has some technical defects that need to be solved urgently. The reduction in the thickness of the structure leads to the tensile stress at the bottom of the asphalt surface layer, the fatigue damage rate of the structure course, and the increase in the interlayer shear force. The traditional wear course is more prone to fatigue cracking, rolling, peeling, and other diseases [17-20].

The objective of this paper is to study the performance and adhesion behavior of ultrathin wear course using calcined bauxite as aggregate. In this paper, the calcined bauxite ultrathin wear course was designed, and then the hightemperature stability, crack resistance, water stability, and interlayer adhesion of the bauxite antiskid wear course were investigated using the rutting test, low-temperature bending test, water stability test, salt spray erosion test, salt spraydynamic water flushing test, oblique shear test, and pullout test. The result showed that the water stability, low- temperature deformation ability, and ability to resist salt erosion were improved by adding calcined bauxite with nonammonia antistripping agent and polyphosphoric acid. This study provides the widespread use of calcined bauxite aggregates in road pavements, improving the durability of ultrathin wear course asphalt pavements.

\section{Materials and Methods}

\subsection{Materials}

2.1.1. Asphalt and Aggregate. SK-90 matrix asphalt was used in this study, and its technical indicators are shown in Table 1. Bauxite aggregates, granite, and limestone aggregates are also used, with their chemical compositions shown in Table 2. The physical technical indicators of 90\# calcined bauxite are shown in Table 3, and finely ground limestone powder was used as mineral powder. According to the SMA5 gradation requirements, the required ratio of aggregates for each grade was determined. The synthetic gradation of the three aggregates meets the requirements.

2.1.2. Fiber Stabilizer and Admixture. Fiber stabilizer has a very significant effect on the performance of SMA asphalt mixture, choosing high-quality lignin fiber is of great significance to the design of SMA asphalt mixture, and its technical indicators are shown in Table 4 . The selected additives are nonammonia antistripping agents and polyphosphoric acids. SBS adopts a YH-791 (1301) modifier produced by Sinopec Baling Petrochemical, and the mixing amount is $4 \%$ when modifying asphalt. The rubber powder modifier used waste heavy-duty vehicle tires as raw materials and was pulverized at room temperature to prepare the rubber powder. The dose of ammonia antistripping agent was $2.0 \%$ and the dose of polyphosphoric acid was $1.5 \%$.

\subsection{Methods}

2.2.1. Rutting Test. The high-temperature stability of asphalt mixture is defined as the ability of asphalt mixture to resist high-temperature diseases such as rutting, waves, shifting, and crowding under long-term vehicle load under the condition of high road temperature (above $60^{\circ} \mathrm{C}$ ). The rutting test is used to evaluate the high-temperature stability of the asphalt mixture. The test time is about $1 \mathrm{~h}$, and the rut depth reaches $25 \mathrm{~mm}$. Record the rut deformation $d_{1}$ and $d_{2}$ at $45 \mathrm{~min}$ and $60 \mathrm{~min}$, respectively, to an accuracy of $0.01 \mathrm{~mm}$. The dynamic stability of asphalt mixture is calculated according to formula (1):

$$
\mathrm{DS}=\frac{\left(t_{2}-t_{1}\right) \times N}{d_{2}-d_{1}} \times C_{1} \times C_{2},
$$

where DS is the dynamic stability of asphalt mixture (times/ $\mathrm{mm}) ; d_{1}$ is the amount of deformation with loading time $t_{1}$; $d_{2}$ is the amount of deformation with loading time $t_{2} ; C_{1}$ is the type coefficient of testing machine; $C_{2}$ is the specimen coefficient; $N$ is the return rolling speed of test wheel. 
TABLE 1: Technical properties of SK-90\# asphalt binder.

\begin{tabular}{|c|c|c|c|c|c|}
\hline \multicolumn{2}{|c|}{ Item } & Unit & Result & Technical requirements & Specification \\
\hline \multicolumn{2}{|c|}{ Penetration $\left(25^{\circ} \mathrm{C}, 100 \mathrm{~g}, 5 \mathrm{~s}\right)$} & $0.1 \mathrm{~mm}$ & 92 & $80 \sim 100$ & ASTM D5-97 \\
\hline \multicolumn{2}{|c|}{ Ductility $\left(10^{\circ} \mathrm{C}\right)$} & $\mathrm{cm}$ & $>100$ & $\geq 45$ & ASTM D113-99 \\
\hline \multicolumn{2}{|c|}{ Softening point } & ${ }^{\circ} \mathrm{C}$ & 48.3 & $\geq 45$ & ASTM D36-06 \\
\hline \multicolumn{2}{|c|}{ Density $\left(15^{\circ} \mathrm{C}\right)$} & $\mathrm{g} / \mathrm{cm}^{3}$ & 0.981 & - & ASTM D70-76 \\
\hline \multirow{3}{*}{$\operatorname{RTFOR}\left(163^{\circ} \mathrm{C}, 75 \mathrm{~min}\right)$} & Penetration ratio $\left(25^{\circ} \mathrm{C}\right)$ & $\%$ & 71.3 & $\geq 57$ & ASTM D5-97 \\
\hline & Mass loss & $\%$ & -0.26 & $\leq \pm 0.8$ & ASTM D2872-04 \\
\hline & Ductility $\left(10^{\circ} \mathrm{C}\right)$ & $\%$ & 14 & $\geq 8$ & ASTM D113-99 \\
\hline
\end{tabular}

TABLE 2: Chemical composition of aggregate.

\begin{tabular}{lccccccccccc}
\hline \multirow{2}{*}{ Aggregate } & \multicolumn{10}{c}{ The content of component (\%) } \\
& $\mathrm{SiO}_{2}$ & $\mathrm{TiO}_{2}$ & $\mathrm{Al}_{2} \mathrm{O}_{3}$ & $\mathrm{TFe}_{2} \mathrm{O}_{3}$ & $\mathrm{MnO}$ & $\mathrm{MgO}$ & $\mathrm{CaO}$ & $\mathrm{Na}_{2} \mathrm{O}$ & $\mathrm{K}_{2} \mathrm{O}$ & $\mathrm{P}_{2} \mathrm{O}_{5}$ & $\mathrm{LOI}$ \\
\hline Calcined bauxite & 6.74 & 3.21 & 86.48 & 1.55 & 0.01 & 0.12 & 0.72 & $<0.01$ & 0.15 & 0.23 & 0.55 \\
Granite & 66.64 & 0.38 & 15.94 & 2.7 & 0.16 & 0.05 & 3.71 & 4.41 & 1.86 & 0.11 & 0.01 \\
Limestone & 6.65 & 0.038 & 0.68 & 0.21 & 0.004 & 0.71 & 51.1 & 0.03 & 0.15 & 0.013 & 0.01 \\
\hline
\end{tabular}

TABle 3: Technical indexes of bauxite aggregate.

\begin{tabular}{lcccc}
\hline Item & Unit & Technical requirements & Result & Specification \\
\hline Crush value, $\ngtr$ & $\%$ & 26 & 7.74 & T0316 \\
Los Angeles wear value, $\ngtr$ & $\%$ & 28 & 10.61 & T0317 \\
Apparent density, $\nless$ & - & 2.60 & 3.28 & T0304 \\
Water content, $\ngtr$ & $\%$ & 2.0 & 1.463 & T0304 \\
Needle flake content, $<$ & $\%$ & 1 & 0.54 & T0310 \\
\hline
\end{tabular}

TABLE 4: Technical indexes of fiber.

\begin{tabular}{lcccc}
\hline Item & Ash content $(\%)$ & PH value & Oil absorption & Water content \\
\hline Requirements & $18 \pm 5$ & $7.5 \pm 1.0$ & - & $<5$ \\
Result & 16.8 & 7.5 & 5.6 & 3.1 \\
\hline
\end{tabular}

2.2.2. Low-Temperature Bending Test. Asphalt mixtures with strong ultimate deformability under low-temperature conditions have good low-temperature viscosity and plasticity. The ultimate flexural strain at low temperatures can be used to evaluate the low-temperature performance of asphalt mixtures. The low-temperature bending test is used to evaluate the low-temperature crack resistance of the SMA-5 calcined bauxite asphalt mixture, and the bending tensile stress, strain, and stiffness modulus are calculated by formulae (2)-(4).

$$
\begin{aligned}
\sigma_{0} & =\frac{3 L F_{0}}{2 b h^{2}} \times 10^{-6}, \\
\varepsilon & =\frac{6 h d}{L^{2}}, \\
\varepsilon & =\frac{6 h d}{L^{2}},
\end{aligned}
$$

where $L$ is the span, mm; $b$ and $h$ are the width and height of the trabeculae; $d$ is the deformation at failure (deflection in the middle of the span), mm; $F_{0}$ is the failure load, $N$.
2.2.3. Water Stability Test. Moisture damage is one of the main damage methods of asphalt pavements. Under the action of the vehicle's dynamic load, the water entering the gap of the pavement produces hydrodynamic pressure and the repeated action of vacuum suction and the freeze-thaw cycle. The speed of the aggregate interface causes the asphalt film to peel off the surface of the stone, forming potholes, crowding and deformation, and other damage phenomena on the asphalt pavement. The water stability of the SMA-5 calcined bauxite asphalt mixture was evaluated by the water immersion Marshall test and freeze-thaw splitting test.

2.2.4. Salt Spray Erosion Test. The salt spray erosion is used to simulate the chloride salt corrosion of the test specimen in the outdoor environment. The salt spray test box is used and the corrosion medium is clean water and a $5 \% \mathrm{NaCl}$ solution. Put the Marshall specimens into the test box, and perform the water immersion Marshall test and freezethaw splitting test after 3 days, 6 days, and 9 days of erosion. 
2.2.5. Salt Spray-Dynamic Water Flushing Test. The salt spray erosion is used to simulate the chloride salt corrosion of the test specimen in the environment. The salt spray test box is used and the corrosion medium is clean water and a $5 \% \mathrm{NaCl}$ solution. Marshall specimens were put into the test box and erode for 3 days, 6 days, and 9 days. When the dynamic water scouring test is carried out, the scouring medium is clean water. Pour the above-configured solution into the bucket and make the water surface cover the test piece. The water temperature and hydrodynamic pressures were set to $30^{\circ} \mathrm{C}$ and $0.2 \mathrm{MPa}$, respectively, because a large number of studies showed that the hydrodynamic pressure is closely related to the speed of the vehicle. As the speed of the vehicle increases, the hydrodynamic pressure also rises geometrically. When the vehicle travels at a speed of $60 \mathrm{~km} /$ $\mathrm{h}$, the hydrodynamic pressure generates approximately $0.2 \mathrm{MPa}$. The number of scouring specimens was set to 6000 times, and each group included five parallel test specimens. After different times of scouring, the Marshall specimen was taken out, the splitting strength and Marshall stability were measured, and the ratios of splitting strength and Marshall stability before and after scouring were calculated.

2.2.6. Oblique Shear Test and Pullout Test. The thickness of the ultrathin wear course is $1.5 \sim 2.5 \mathrm{~cm}$. The construction was carried out after the ordinary asphalt mixture surface course was laid. Therefore, due to the insufficient interlayer adhesion performance under the load and shear of the vehicle, the interlayer slippage or even slippage will be caused. Studies have shown that the maximum tensile stress of the ultrathin wear course is the transverse tensile stress, and the maximum shear stress is the transverse shear stress, which mainly occurs at the bottom of the ultrathin wear course. The interlayer oblique shear test and the interlayer pullout test were used to evaluate the interlayer bonding performance of the ultrathin wearing course and the asphalt pavement.

For the failure load of the oblique shear test, the shear strength of the specimen can be calculated according to

$$
\tau=\frac{P}{A} \sin \alpha
$$

where $\tau$ is the shear strength of the specimen (MPa); $P$ is the failure load $(\mathrm{kN}) ; A$ is the shear surface area $\left(\mathrm{m}^{2}\right) ; \alpha$ is the shear angle $\left({ }^{\circ}\right)$.

\section{Results and Discussion}

3.1. High-Temperature Performance. The results of the hightemperature rutting test are shown in Table 5. The hightemperature dynamic stability of the SMA-5 calcined bauxite asphalt mixture is much higher than the specified index, because the high-temperature stability of the asphalt mixture mainly comes from the cohesiveness and adhesion of the asphalt binder. SMA-5 has a dense skeleton structure, and with interembedded skeletons in the mixture and since calcined bauxite aggregates are broken aggregates and are more likely to form good intercalation, SMA-5 calcined bauxite asphalt mixture has excellent resistance to load deformation. Moreover, under high-temperature conditions, the stiffness of asphalt mastic reduces the framework structure and can also improve the supporting effect, so it has excellent high-temperature resistance to rutting. The slight difference in dynamic stability is due to the fact that the nonammonia antistripping agent belongs to the organic solution, which would cause the asphalt to soften, resulting in the decrease of the high-temperature stability of the asphalt mixture. The addition of polyphosphoric acid would increase the viscosity of the asphalt and cause the asphalt to harden it, so the dynamic stability is improved.

3.2. Low-Temperature Performance. The low-temperature crack resistance test results are shown in Table 6, showing that the SMA-5 calcined bauxite asphalt mixture has excellent low-temperature crack resistance, because the lowtemperature crack resistance of the asphalt mixture depends on the tensile strength of the asphalt binder. The selected SBS-modified asphalt has excellent tensile deformation ability, and the grading design of SMA ensures that the mixture of aggregates is filled with rich asphalt mastic, which is fully on the surface of mineral aggregates. Meanwhile, when the temperature drops, the asphalt mixture shrinks and deforms and causes aggregate separation, but the SBS asphalt mastic still has strong bonding ability, so the asphalt mixture as a result has excellent low-temperature crack resistance performance. The addition of nonammonia antistripping will cause the asphalt to soften, so the deformability is enhanced and the addition of polyphosphoric acid would increase the modulus of the asphalt, so the deformability would decrease.

3.3. Water Stability Test. The water stability test results of the SMA-5 calcined bauxite asphalt mixture using the water immersion Marshall test and freeze-thaw splitting test are shown in Table 7. The results show that the SMA-5 calcined bauxite asphalt mixture is water stable. The performance is also better due to two main reasons. The first is that the SBSmodified asphalt and 90\# calcined bauxite aggregate have better adhesion and water damage resistance. The second is that the SMA asphalt mixture has a very small void ratio and poor water permeability, so the mixture is less affected by water. Furthermore, after adding the nonammonia antistripping agent, the water stability was greatly improved. Because the nonammonia antistripping agent is a surface modifier, which can better improve the adhesion of the asphalt and the calcined bauxite aggregate, it resists moisture damage. Also, when polyphosphoric acid is added, the water stability is much more improved, and the addition of polyphosphoric acid could promote the conversion of asphaltene, increase the polarity of the asphalt, and make polar aggregates absorption on the surface easier. It can be seen from the results that the quality of the aggregate itself is good, as well as the reasonable selection and mix ratio design of the asphalt, and as a result, the high-temperature performance, low-temperature performance, and water stability 
TABLE 5: Results of rutting test.

\begin{tabular}{lccc}
\hline Item & Dynamic stability & Deformation (45 min) & Deformation (60 min) \\
\hline Without antistripping agent & 6951 & 1.19 & 1.40 \\
Antistripping agent & 6872 & 1.21 & 1.43 \\
Polyphosphoric acid & 7104 & 1.17 & 1.37 \\
\hline
\end{tabular}

TABLE 6: Results of trabecular bending test.

\begin{tabular}{lccc}
\hline Item & Flexural tensile strength $(\mathrm{MPa})$ & Maximum bending strain $\left(\times 10^{-6}\right)$ & Modulus of flexural stiffness $(\mathrm{MPa})$ \\
\hline Without antistripping agent & 11.51 & 5702 & 2018 \\
Antistripping agent & 11.26 & 5873 & 1917 \\
Polyphosphoric acid & 11.76 & 5507 & 2135 \\
\hline
\end{tabular}

TABLE 7: Results of water stability test.

\begin{tabular}{lcc}
\hline Item & TSR $(\%)$ & MS $_{0}(\%)$ \\
\hline Without antistripping agent & 86.3 & 85.6 \\
Antistripping agent & 90.4 & 91.2 \\
Polyphosphoric acid & 87.7 & 86.9 \\
\hline
\end{tabular}

of the SMA-5 ultrathin wear course asphalt mixture are excellent.

The salt spray erosion is used to simulate the chloride salt corrosion of the test piece in the outdoor environment. The salt spray test box is used with the corrosion medium being clean water and a $5 \% \mathrm{NaCl}$ solution. The Marshall specimens were put into the test box, water immersion Marshall and freeze-thaw splitting tests were performed after 3 days, 6 days, and 9 days of erosion, and the relationship between salt spray erosion time and water stability test is shown in Figure 1. The freeze-thaw splitting strength ratio and the water-immersed Marshall strength ratio of the calcined bauxite both decrease with the extension of the salt spray erosion time, which is due to the salt spray erosion destroying the bonding interface between the asphalt and the calcined bauxite aggregate, thereby showing that it can improve the water stability of calcined bauxite asphalt mixture.

The relationship between the water stability test results and the water immersion tensile strength loss rate is shown in Figure 2. It can be seen that the water immersion tensile strength loss rate has a good correlation with the water stability of the asphalt mixture, because the deterioration of the mechanical properties of the asphalt mixture is mainly caused by the damage of the asphalt and bonding interface between the asphalt and the calcined bauxite aggregate under the conditions of water immersion and the softening of the asphalt. It is similar to the reduction mechanism of the tensile strength of asphalt and calcined bauxite aggregate under water immersion.

The salt spray erosion is used to simulate the chloride salt corrosion of the test piece in the field environment. The salt spray test box is used, and the corrosion medium is clean water and a $5 \% \mathrm{NaCl}$ solution. The Marshall specimens were put into the test box and erode for 3 days, 6 days, and 9 days. When the dynamic water scouring test is carried out, the scouring medium is clean water. The standard Marshall specimens of the SMA- 5 calcined bauxite were fixed with 50 times of double-sided compaction according to the above grading and curing for 24 hours at room temperature on the mold, and the above-mentioned solution was poured into the barrel ensuring that the water surface was just over the test specimens. The water temperature was set to $30^{\circ} \mathrm{C}$ and the hydrodynamic pressure was set to $0.2 \mathrm{MPa}$, because a large number of studies have shown that the hydrodynamic pressure is closely related to the speed of the vehicle. As the vehicle speed increases, the hydrodynamic pressure also rises geometrically. When the vehicle travels at a speed of $60 \mathrm{~km} / \mathrm{h}$, the hydrodynamic pressure generated is approximately $0.2 \mathrm{MPa}$. The number of scouring specimens was set to 6000 times, and each group included five parallel test specimens. After different times of scouring, the Marshall specimens were taken out, the splitting strength and Marshall stability were measured, and the splitting strength ratio before and after scouring as well as the Marshall stability ratio was calculated.

The relationship between salt spray erosion time and dynamic water erosion test results is shown in Figure 3. It can be seen from the results that, compared to the water stability test, the dynamic stability and split strength ratio of the calcined bauxite Marshall specimens after being washed by dynamic water show a greater decrease, and the drop rate is greater than that under clean water conditions. It was found that the addition of a nonammonia antistripping agent and polyphosphoric acid can significantly improve the ability of the calcined bauxite asphalt mixture to resist erosion and erosion by dynamic water. Furthermore, the improvement of the resistance to dynamic water erosion in the calcined bauxite asphalt mixture is greater with the addition of nonammonia antistripping agent than with the addition of polyphosphoric acid.

The relationship between the results of the scouring test and the loss of pullout strength in water is shown in Figure 4. It can be seen that the loss rate of pullout strength in water has a poor correlation with the results of the dynamic water scour test of asphalt mixture. This is because, during the 


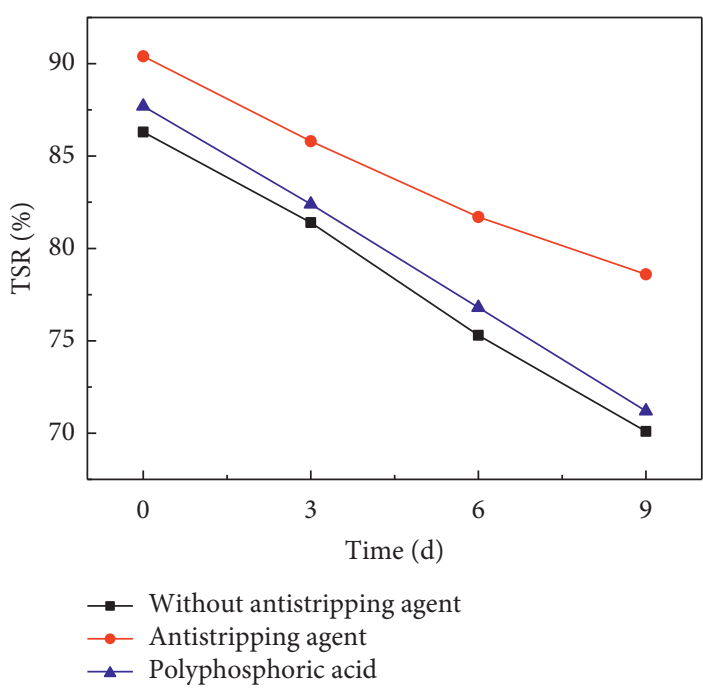

(a)

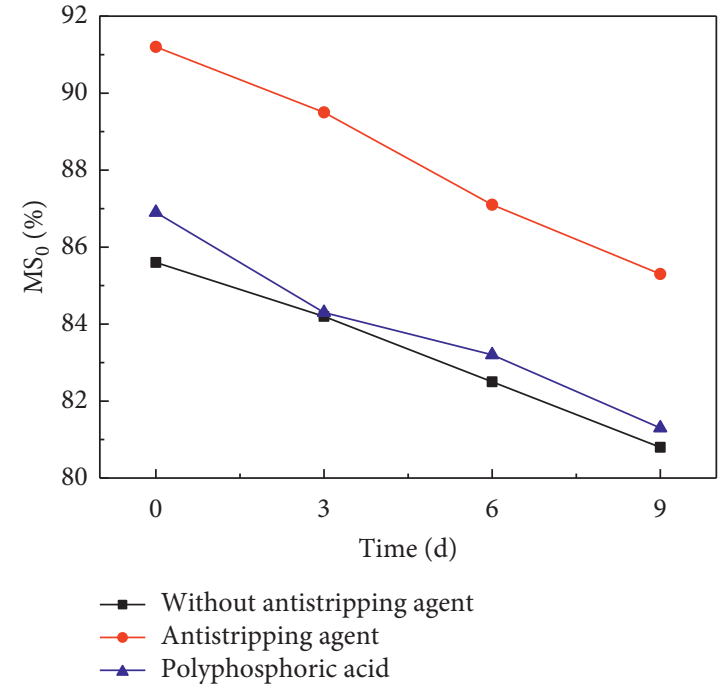

(b)

FIgURE 1: Relationship between salt spray erosion time and water stability test results. (a) TSR. (b) $\mathrm{MS}_{0}$.

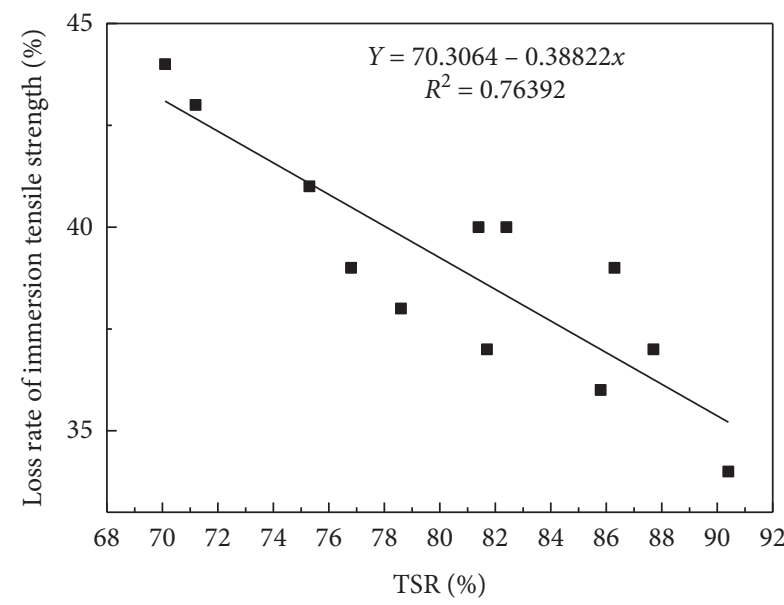

(a)

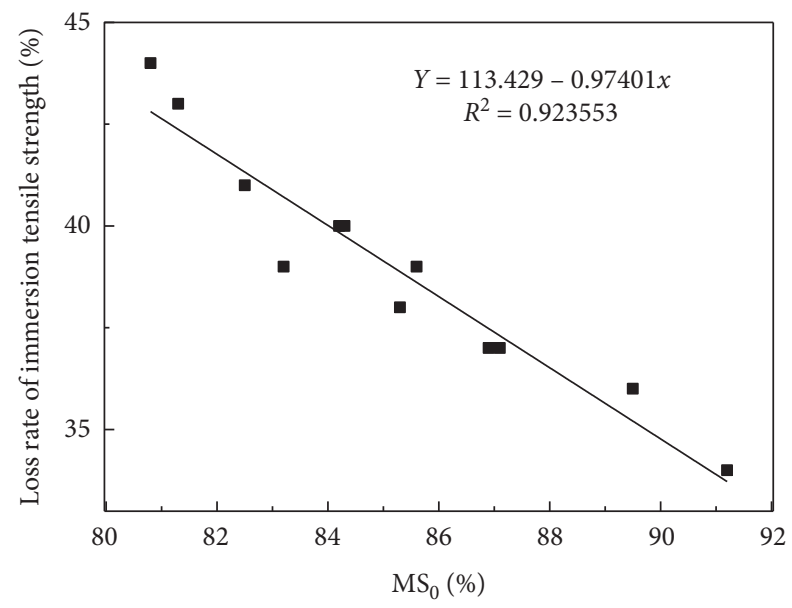

(b)

FIGURE 2: Relationship between water stability test results and water immersion tensile strength loss rate. (a) TSR. (b) MS .

process of dynamic water scour, there is not only water erosion and displacement but also dynamic water pressure scour. The joint action aggravated the destruction of the bonding interface between the asphalt and the calcined bauxite aggregate, while the water immersion pullout test only simulated the erosion under static water conditions, so the correlation between the two test results was poor.

3.4. Adhesion between Layer Tests. The results of the interlayer shear test are shown in Table 8 . The results indicated that the use of different emulsified asphalt spreads between layers has a greater impact on the interlayer shear strength. SBS modified asphalt was used as the adhesive layer material to increase the shear strength of the layer frame is clear, because SBS-emulsified modified asphalt has higher viscosity than base-emulsified asphalt, stronger tensile properties, and better interlayer bonding effect. The addition of admixtures to the asphalt mixture has little effect on the interlayer shear strength because the most important factors affecting the interlayer shear performance are the type and amount of emulsified asphalt. During the service of asphalt pavement, the contact state of the surface layer would change under the action of driving load, which would cause the stress redistribution of the internal structure of the pavement and may convert the compressive stress into tensile stress. Therefore, it is necessary to evaluate the pullout strength of the surface layer frame during the design of the ultrathin wear course. The results of the interlayer shear test are shown in Table 9. Similar to the layer frame shear strength, the use of SBS-emulsified modified asphalt could significantly improve the interlayer pullout strength, but the 


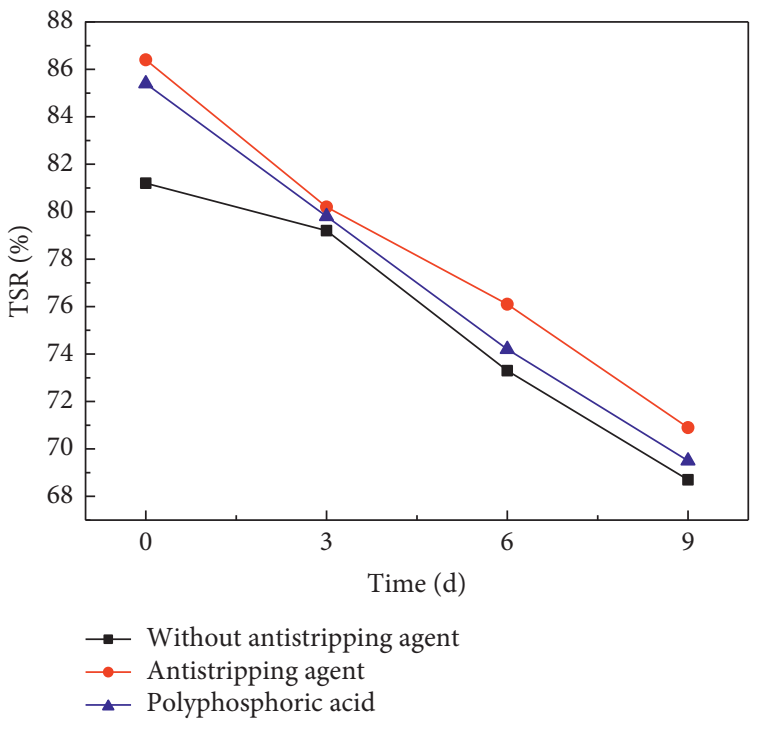

(a)

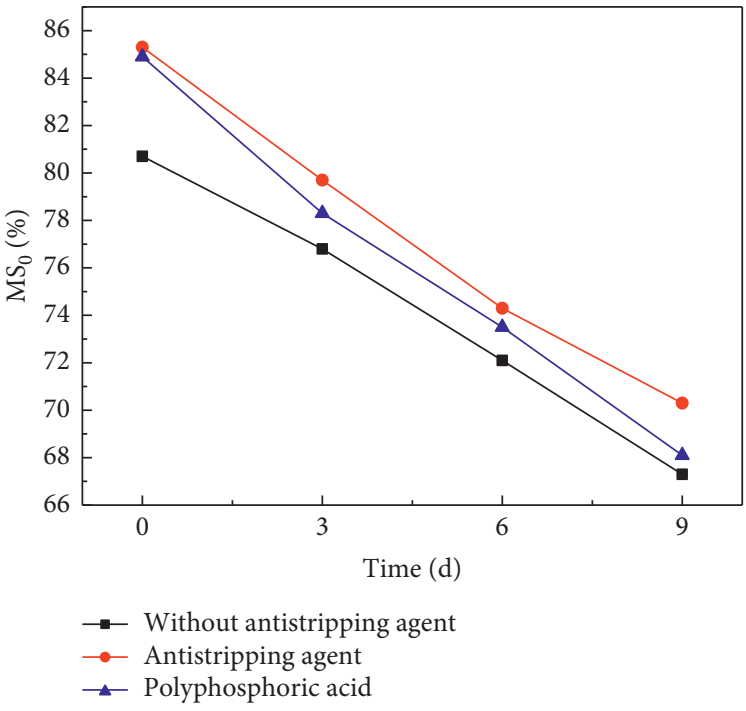

(b)

FIGURE 3: Relationship between salt spray erosion time and dynamic water erosion test results. (a) TSR. (b) $\mathrm{MS}_{0}$.

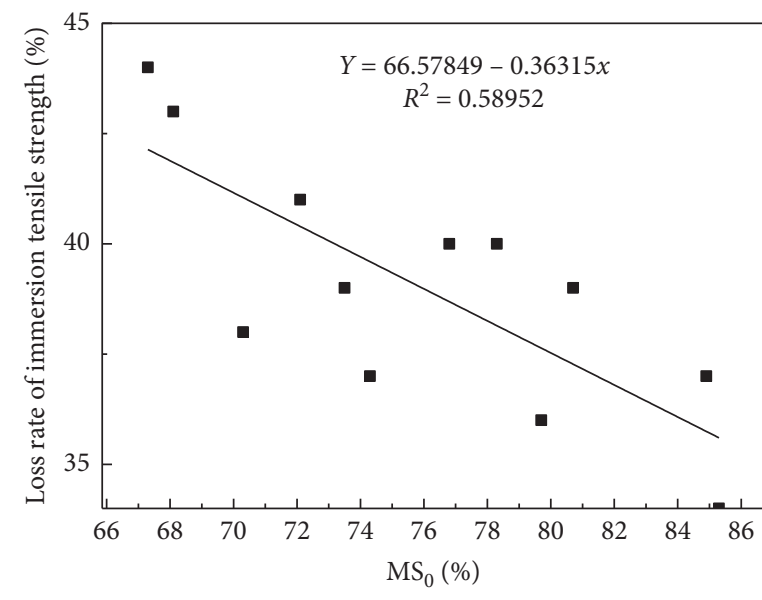

(a)

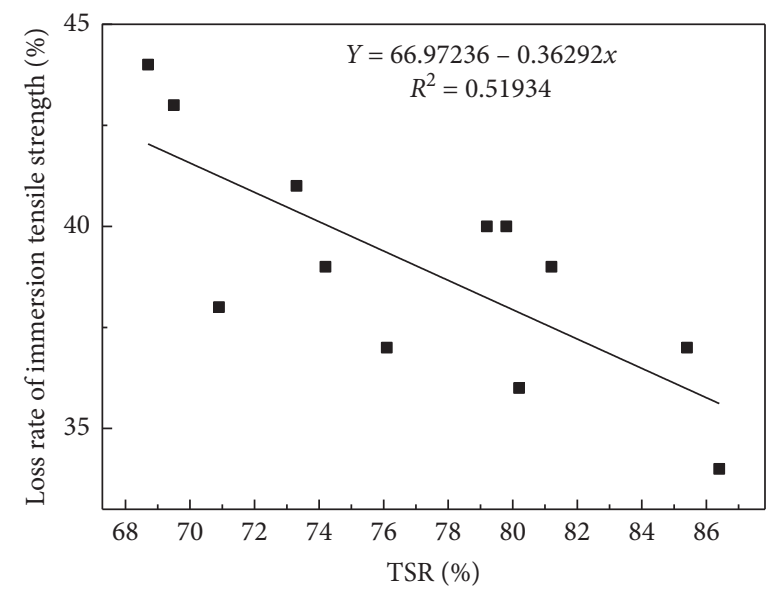

(b)

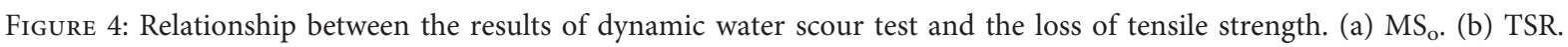

TABLE 8: Results of interlayer shear test.

\begin{tabular}{lcr}
\hline \multirow{2}{*}{ Item } & \multicolumn{2}{c}{$\begin{array}{c}\text { Shear strength between layers (MPa) } \\
\text { SBS-emulsified asphalt }\end{array}$} \\
\hline Without antistripping agent & Base-emulsified asphalt & 2.65 \\
Antistripping agent & 2.21 & 2.69 \\
Polyphosphoric acid & 2.17 & 2.73 \\
\hline
\end{tabular}


TABLE 9: Results of interlayer pullout test.

\begin{tabular}{lcr}
\hline Item & \multicolumn{2}{c}{$\begin{array}{c}\text { Pullout strength between layers (MPa) } \\
\text { SBS-emulsified asphalt }\end{array}$} \\
\hline Without antistripping agent & Base-emulsified asphalt & 1.57 \\
Antistripping agent & 1.16 & 1.55 \\
Polyphosphoric acid & 1.17 & 1.52 \\
\hline
\end{tabular}

interlayer pullout strength is much smaller than the interlayer shear strength, because in the shear failure process, the emulsified asphalt does have not only a cohesive effect but also an intermixing effect.

\section{Conclusions}

In this paper, the gradation design of the calcined bauxite asphalt mixture was carried out, subsequently, its road performance was tested, and the conclusions are as follows:

(1) Calcined bauxite asphalt mixture without an antistripping agent has good high-temperature stability, low-temperature crack resistance, and water stability, as well as good interlayer adhesion. It is recommended to use polyphosphoric acid to improve the adhesion between asphalt and calcined bauxite aggregate in high temperature, drought, and heavy traffic areas.

(2) The addition of a nonammonia antistripping agent can significantly improve the water stability of the calcined bauxite asphalt mixture and its ability to resist salt erosion and can soften the asphalt and improve its low-temperature deformation ability. The addition of polyphosphoric acid can improve the adhesion between asphalt and calcined bauxite aggregate and the high-temperature performance of asphalt calcined bauxite asphalt mixture but has limited effects in improving its water stability and resistance to salt erosion.

(3) The tensile strength loss rate of asphalt and calcined bauxite in water has a good correlation with the water stability of Marshall specimens at water immersion conditions. The tensile strength of the water immersion pull test can be used to evaluate the relationship between asphalt and aggregate adhesion. The water stability of the asphalt mixture is predicted by the loss rate of pullout strength in water.

(4) The bauxite can be used in asphalt mixtures instead of aggregates and has excellent performance, which is conducive to improving the durability of pavements. However, economics needs to be further considered to reduce costs.

\section{Data Availability}

The data used to support the findings of this study are included within the article.

\section{Conflicts of Interest}

The authors declare that they have no conflicts of interest.

\section{Acknowledgments}

This research was funded by the Science and Technology Project of Hebei Department (JD-202005).

\section{References}

[1] L. Geng, T. Ma, J. Zhang et al., "Research on performance of a dense graded ultra-thin wearing course mixture," Applied Sciences, vol. 7, no. 8, 2017.

[2] W. Cui, K. Wu, X. Cai et al., "Optimizing gradation design for ultra-thin wearing course asphalt," Materials, vol. 13, no. 1, 2020.

[3] H. Li, W. Wang, W. Li, A. Taoum, G. Zhao, and P. Guo, "Replacement of limestone with volcanic stone in asphalt mastic used for road pavement," Arabian Journal for Science and Engineering, vol. 44, no. 10, pp. 8629-8644, 2019.

[4] L. Cong, T. Wang, L. Tan, J. Yuan, and J. Shi, "Laboratory evaluation on performance of porous polyurethane mixtures and OGFC," Construction and Building Materials, vol. 169, pp. 436-442, 2018.

[5] F. Yang, H. Li, G. Zhao, P. Guo, and W. Li, "Mechanical performance and durability evaluation of sandstone concrete," Advances in Materials Science and Engineering, vol. 2020, no. 13, 10 pages, Article ID 241749, 2020.

[6] K. Krummenauer and J. J. de Oliveira Andrade, "Incorporation of chromium-tanned leather residue to asphalt microsurface layer," Construction and Building Materials, vol. 23, no. 1, pp. 574-581, 2009.

[7] Z. Qian and Q. Lu, "Design and laboratory evaluation of small particle porous epoxy asphalt surface mixture for roadway pavements," Construction and Building Materials, vol. 77, pp. 110-116, 2015.

[8] A. Vaitkus, T. Andriejauskas, V. Vorobjovas, A. Jagniatinskis, B. Fiks, and E. Zofka, "Asphalt wearing course optimization for road traffic noise reduction," Construction and Building Materials, vol. 152, pp. 345-356, 2017.

[9] Y. Sheng, H. Jia, H. Lv et al., "Study on mesoscopic mechanics of recycled asphalt mixture in the indirect tensile test," Mathematical Problems in Engineering, vol. 2020, Article ID 6621275, 12 pages, 2020.

[10] H. Li, F. Zhang, Z. Feng et al., "Study on waste engine oil and waste cooking oil on performance improvement of aged asphalt and application in reclaimed asphalt mixture," Construction and Building Materials, vol. 276, Article ID 122138, 2021.

[11] H. Ziari, A. Moniri, P. Bahri, and Y. Saghafi, "The effect of rejuvenators on the aging resistance of recycled asphalt mixtures," Construction and Building Materials, vol. 224, pp. 89-98, 2019.

[12] J. Wan, S. Wu, Y. Xiao et al., "Enhanced ice and snow melting efficiency of steel slag based ultra-thin friction courses with steel fiber," Journal of Cleaner Production, vol. 236, 2019. 
[13] M. Hu, L. Li, and F. Peng, "Laboratory investigation of OGFC5 porous asphalt ultra-thin wearing course," Construction and Building Materials, vol. 219, pp. 101-110, 2019.

[14] M. Deng, Y. Ding, Z. He et al., "Investigation on performance and nano-adhesion behavior of ultra-thin wearing course using polyurethane as binder," Construction and Building Materials, vol. 278, 2021.

[15] J. Yu, F. Chen, W. Deng et al., "Design and performance of high-toughness ultra-thin friction course in south China," Construction and Building Materials, vol. 246, 2020.

[16] A. Ameli, R. Babagoli, M. Khabooshani et al., "Permanent deformation performance of binders and stone mastic asphalt mixtures modified by SBS/montmorillonite nanocomposite," Construction and Building Materials, vol. 239, 2020.

[17] A. Ongel, K. Erwin, Q. Lu et al., "Comparison of surface characteristics and pavement/tire noise of various thin asphalt overlays," Road Materials and Pavement Design, vol. 9, no. 2, 2008.

[18] X. Hu, Y. Lei, H. Wang, P. Jiang, X. Yang, and Z. You, "Effect of tack coat dosage and temperature on the interface shear properties of asphalt layers bonded with emulsified asphalt binders," Construction and Building Materials, vol. 141, pp. 86-93, 2017.

[19] G. G. Al-Khateeb and A. Shenoy, "Mixture-property-independent asphalt film thickness model," Materials Today Communications, vol. 19, pp. 482-486, 2019.

[20] K. Sobban and M. Mashnad, "Tensile strength and toughness of soil-cement-fly-ash composite reinforced with recycled high-density polyethylene strips," Journal of Materials in Civil Engineering, vol. 14, no. 2, pp. 177-184, 2002. 